\title{
Corrigendum to "Enhanced Measurement of Paper Basis Weight Using Phase Shift in Terahertz Time-Domain Spectroscopy"
}

\author{
Mengbao Fan $\mathbb{D}^{1},{ }^{1}$ Binghua Cao $\mathbb{D},{ }^{2}$ and Guiyun Tian $^{3}$ \\ ${ }^{1}$ School of Mechatronic Engineering, China University of Mining and Technology, Xuzhou 221116, China \\ ${ }^{2}$ School of Information and Control Engineering, China University of Mining and Technology, Xuzhou 221116, China \\ ${ }^{3}$ School of Electrical and Electronic Engineering, Newcastle University, Newcastle upon Tyne NE1 7RU, UK
}

Correspondence should be addressed to Binghua Cao; caobinghua@cumt.edu.cn

Received 20 December 2017; Accepted 26 December 2017; Published 20 February 2018

Copyright (c) 2018 Mengbao Fan et al. This is an open access article distributed under the Creative Commons Attribution License, which permits unrestricted use, distribution, and reproduction in any medium, provided the original work is properly cited.

In the article titled "Enhanced Measurement of Paper Basis Weight Using Phase Shift in Terahertz TimeDomain Spectroscopy" [1], an acknowledgment should be added as follows:

"This work is supported by Fundamental Research Foundation for the Central Universities under Grant 2013QNA47, Six Talent Peaks Project in Jiangsu Province under Grant ZBZZ-041, and Priority Academic Program Development of Jiangsu Higher Education Institutions. Dr. Binghua Cao and Dr. Mengbao Fan would like to acknowledge China University of Mining and Technology and Jiangsu Provincial Department of Education of China for sponsoring their visit to Newcastle University as academic visitors."

\section{References}

[1] M. Fan, B. Cao, and G. Tian, "Enhanced Measurement of Paper Basis Weight Using Phase Shift in Terahertz Time-Domain Spectroscopy," Journal of Sensors, vol. 2017, Article ID 3520967, 14 pages, 2017. 


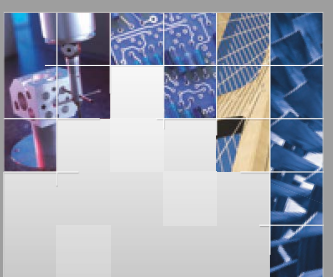

\section{Enfincering}
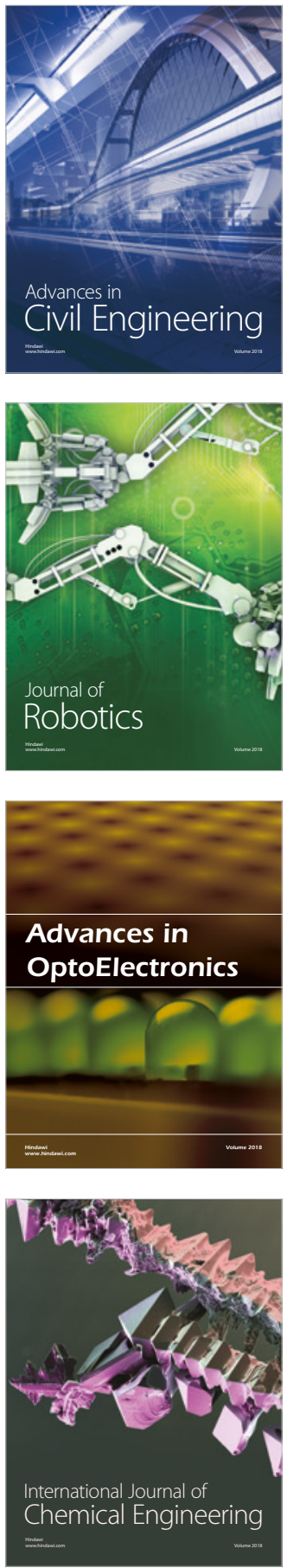

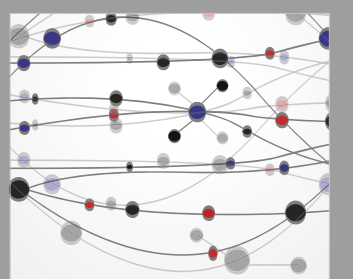

\section{Rotating \\ Machinery}

The Scientific World Journal

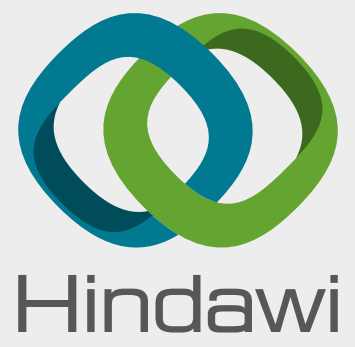

Submit your manuscripts at

www.hindawi.com
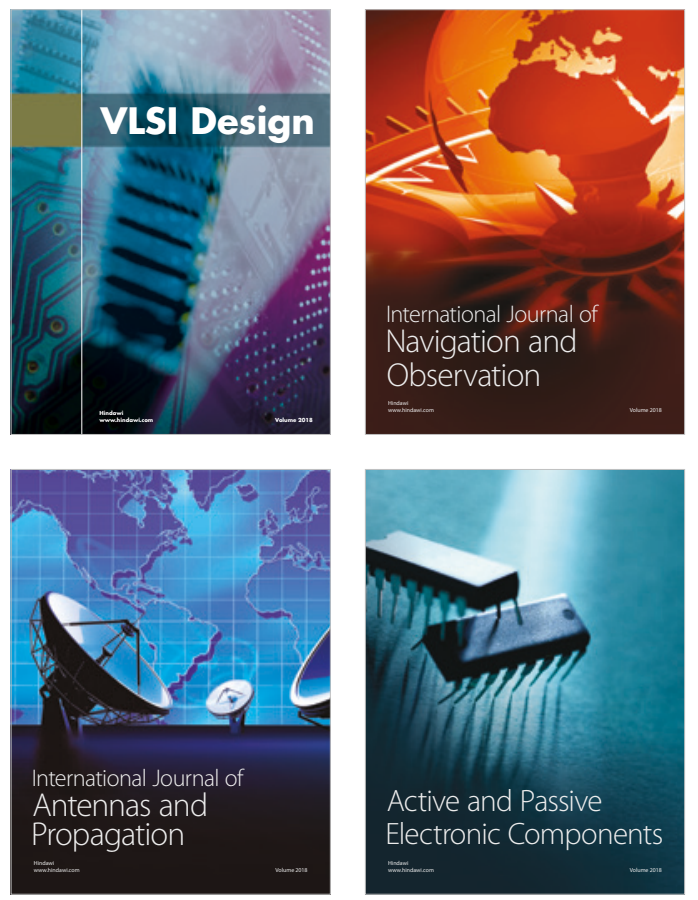
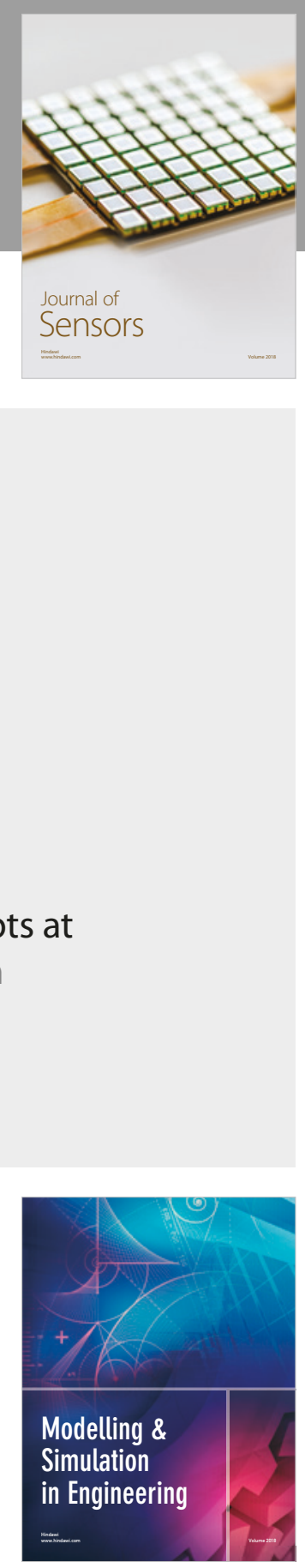

\section{Advances \\ Multimedia}
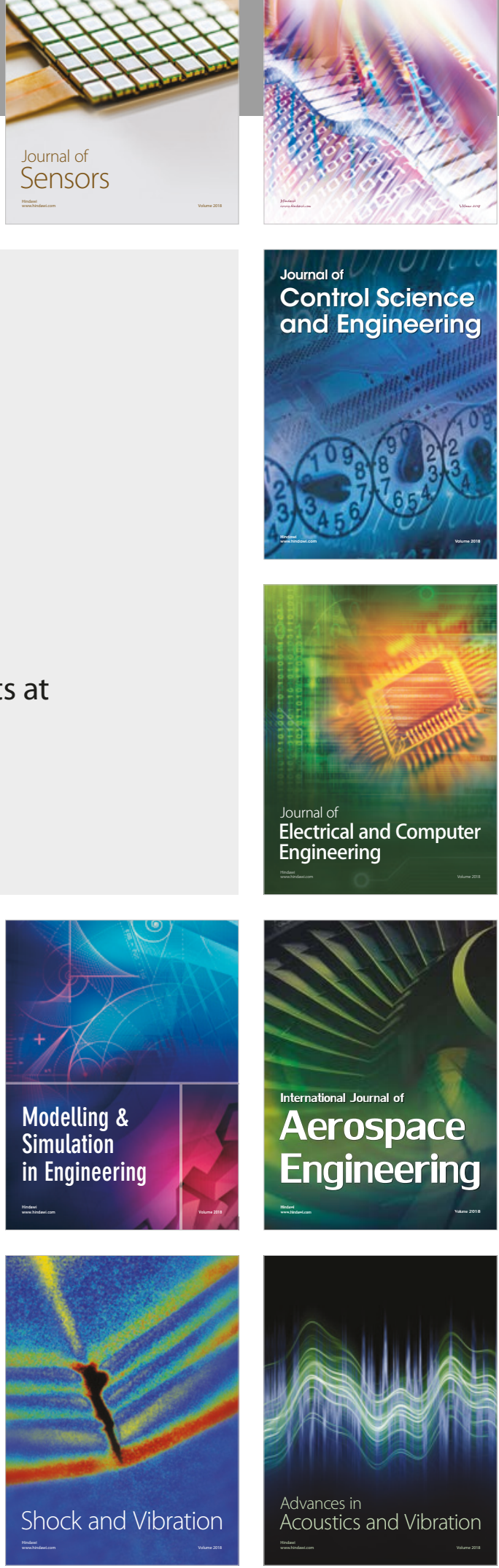